\title{
São assim os baianos': entre afinidades eletivas e regionais a presença de Anísio Teixeira e dos intelectuais baianos no Ministério da Educação nos anos 1950 e 1960
}

Fernando César Ferreira Gouvêa Universidade Federal Rural do Rio de Janeiro gouveafcf@uol.com.br

(1) Título do livro de autoria de Péricles Madureira de Pinho publicado em

\begin{abstract}
Resumo: O presente trabalho busca compreender a trajetória e a permanência dos intelectuais baianos Anísio Teixeira, Jayme Abreu, Almir de Castro e Péricles Madureira de Pinho à frente dos principais setores pedagógicos do Ministério da Educação no período de 1951 a 1964. Cabe ressaltar a centralidade de Anísio Teixeira neste processo haja vista que os espaços de poder por ele ocupados, como Secretário Geral da Coordenação de Aperfeiçoamento de Pessoal de Nível Superior (1951), Diretor do Instituto Nacional de Estudos e Pesquisas Educacionais (1952) e Diretor do Centro Brasileiro de Pesquisas Educacionais (1955), propiciaram os convites para os demais intelectuais baianos exercerem o papel de diretores executivos nas referidas instituições. A metodologia terá como esteio a confrontação entre memórias, entrevistas, acervos, correspondências, relatórios institucionais e impressos pedagógicos na perspectiva de apreender a rede que deu a sustentação para a permanência dos referidos atores no âmbito da burocracia estatal, mais especificamente na pasta atinente à educação que assistiu à passagem de 13 ministros titulares no período em tela. Trata-se de uma pesquisa que tem a intenção de pensar a construção de uma forma de politização do pensamento e ação educacional de atores no seio de uma rede de tramas político-partidárias complexas num modelo de Estado de orientação nacional-desenvolvimentista.
\end{abstract}

Palavras-chave: Anísio Teixeira. Trajetória de Intelectuais. Intelectuais baianos. Ministério da Educação. Brasil, 1950-1960.

\section{Introdução}

Nascidos ou não na Bahia, baianos são os que ali vivendo com ela se identificam constituindo expressões de sua multiplicidade de espírito. Ainda sem atentar para a generalização do homem do Sul - todo nortista é baiano - há entre os 'baianos da Bahia' (como os chamava Afrânio Peixoto) tipos e atitudes variados, antagônicos até. A caricatura do extrovertido e bem falante, sempre utilizada para focalizá-los, não se ajusta a um meio que apresenta gente diversa, desde a silenciosa e reticente, incluindo a refletida e discreta, até à palavrosa e retumbante, misturada na mais expressiva das comunidades do País. (PINHO, 1960, p. 11-12)

O presente trabalho busca compreender a trajetória e a permanência dos intelectuais baianos Anísio Teixeira, Jayme Abreu, Almir de Castro e Péricles Madureira de Pinho à frente dos princi- 
pais setores pedagógicos do Ministério da Educação no período de 1951 a 1964. A metodologia terá como esteio a confrontação entre memórias, entrevistas, acervos, correspondências, relatórios institucionais e impressos pedagógicos na perspectiva de apreender a rede que deu a sustentação para a permanência dos referidos atores no âmbito da burocracia estatal, mais especificamente na pasta atinente à educação que assistiu à passagem de 13 ministros titulares no período em tela.

Há quase 20 anos pesquisando as instituições dirigidas por Anísio Teixeira, o acúmulo de cargos e funções em diferentes órgãos nunca escapou aos olhos e nem da crítica à excessiva centralização gerada pela mesma. Acúmulo que se manifestou candente nos anos 1950 e 1960. O ano de 1955 é paradigmático: Teixeira está à frente da Coordenação de Aperfeiçoamento de Pessoal de Nível Superior (CAPES) (desde 1951), do Instituto Nacional de Estudos e Pesquisas Educacionais (INEP) (desde 1952), passou em 1955, também, a ser diretor do Centro Brasileiro de Pesquisas Educacionais (CBPE), presidente da Sociedade Brasileira para o Progresso da Ciência (SBPC) e membro efetivo do Conselho Curador do Instituto Superior de Estudos Brasileiros (ISEB) - uma centralização excessiva de poder. Esta centralização também suscitou a necessidade de um número expressivo de colaboradores a fim de que as instituições continuassem a funcionar na ausência de Teixeira. Nesse sentido, não foram encontros casuais e, sim, fruto da rede estabelecida de relações.

A metodologia utilizada repousa na pesquisa de caráter documental e histórico, especialmente no que concerne à História Política que entende o intelectual como "ator do político", do ator que apresenta "um engajamento na vida da cidade" e dos seus projetos e que também pode ser a testemunha ou a consciência destes movimentos no que refere à assinatura de manifestos e abaixo-assinados, criação de revistas e demais ações que se estendam a outros campos sociais. (SIRINELLI, 2003, p. 231)

Há que se destacar que se trata de um ator do político que opera em rede. Segundo Elias (1994, p. 35), nessa rede

[...] Muitos fios isolados ligam-se uns aos outros. No entanto, nem a totalidade da rede nem a forma assumida por cada um dos seus fios podem ser compreendidas em termos de um único fio, ou mesmo de todos eles, isoladamente considerados; a rede 
só é compreensível em termos da maneira como eles se ligam, de sua relação recíproca [...].

No que tange às fontes, foram proveitosos os depoimentos, documentos institucionais, correspondências e biografias. Sobre as últimas, acompanho o pensamento de Levillain na afirmação sobre o seu status historiograficamente incerto. Entretanto, o mesmo autor afirma que "[...] não é com base no biografado que se dividem as biografias literárias e as biografias históricas, nem com base na escrita, o que equivale a dizer no estilo, e sim com base na parte de ficção que entra nas primeiras e deve ser proibida nas segundas por razões de método [...]". (LEVILLAIN, 2003, p. 155) Portanto, neste estudo, somente a biografia histórica alimenta as problematizações propostas.

\section{A construção de uma trajetória}

Analisar a trajetória de Teixeira significa um esforço para a compreensão dos seguintes pontos: as afinidades regionais como elemento de sustentação de um ator num complexo contexto político; as ligações de um "apolítico" com representantes de partidos políticos de matizes diferenciadas; as relações com outros educadores no âmbito de diferentes instituições, especialmente com o grupo de educadores, sociólogos e antropólogos constituído em São Paulo; as relações de poder e a posterior capitalização destas relações para as permanências à frente do poder público federal e, por fim, a descentralização centralizadora do Ministério quando o mesmo sujeito detentor de um projeto, Anísio Teixeira, dirige as instituições mencionadas e participa em cargos de relevância em uma série de outras instituições nacionais e internacionais numa rede de relações amplas e diversificadas. (VELHO, 1997) Mais do que isto, à noção de projeto acrescenta-se a ideia de que "[...] visto dessa maneira, o que estende o horizonte de expectativa é o espaço de experiência aberto para o futuro. As experiências liberam os prognósticos e os orientam". (KOSELLECK, 2006, p. 313) Exatamente, no espelhamento entre o espaço de experiência e o horizonte de expectativa residem as buscas das relações e dos projetos estabelecidos entre Teixeira e demais intelectuais.

Anísio Teixeira assumiu pela primeira vez um cargo público em 1924. Foi convidado pelo recém-empossado Governador da 
Bahia Góis Calmon para titular da Inspetoria Geral de Ensino. Em 1928, após sua primeira viagem aos Estados Unidos, publica o livro Aspectos americanos da educação que foi distribuído gratuitamente pela Diretoria Geral de Instrução e começa a trazer as marcas das profundas renovações e transformações pelas quais passaria. No mesmo ano, apresenta como balanço de sua gestão à frente da referida Diretoria, um relatório repleto de estatística escolar, mas que tem na crítica que faz à educação oferecida à população, uma acurada análise do ensino secundário e uma retomada da premência da valorização da escola primária e do professor na sua formação e na sua prática.

Ao regressar da segunda viagem aos Estados Unidos, onde obtém o título de Master of Arts, Anísio encontra em 1929 um novo governador e apresenta um documento intitulado "Sugestões para a reorganização progressiva do Sistema Educacional Baiano" - na verdade um relatório (propositivo) das experiências vividas no exterior. Cito este documento por entender que ele revela um "outro" Anísio do ponto de vista intelectual. Um Anísio que bebeu em novas fontes uma nova filosofia: o progressivismo de Dewey. As proposições contidas no documento não foram aceitas pelo novo governador Vital Soares. Tal situação impôs a exoneração de Anísio do cargo de Inspetor Geral de Ensino e a sua nomeação para professor de Filosofia e História da Educação na Escola Normal em Salvador, mantendo a sua ligação com a educação e, principalmente, com a formação de professores.

Em 1931, aceitou o convite de Francisco Campos, Ministro de Estado dos Negócios de Educação e Saúde Pública, para o cargo de Diretor do Ensino Secundário. A tarefa de organizar o ensino secundário durou pouco tempo, pois meses depois recebeu um convite do prefeito Pedro Ernesto para ocupar a Diretoria Geral de Instrução Pública do Distrito Federal. Em 1935, demitiu-se do cargo por pressões dos setores reacionários ligados ao governo Vargas.

Após o compulsório afastamento de mais de uma década da vida pública do país, a convite de Otávio Mangabeira - governador eleito da Bahia - Anísio assumiu o posto de Secretário de Educação e Saúde, em 1947.

Retornou ao âmbito do governo federal em 1951 e, a partir deste momento, esteve à frente de diversas instituições, a saber: 
(2) Atualmente, Instituto Naciona de Estudos e Pesquisas Educacionais Anísio Teixeira.

(3) Nasceu em Salvador, Bahia, no dia 16 de fevereiro de 1909 Formou-se em Medicina na faculdade de Medicina da Bahia. A partir de 1927, exerceu o cargo de Inspetor de Ensino no Ginásio da Bahia. Em 1931, foi nomeado Inspetor Federal do Ministério da Educação e Saúde para o Ensino Secundário. Faleceu no Rio de Janeiro em 1973 (BRITTO, 1999).

(4) Nasceu em Salvador, Bahia no dia 27 de agosto de 1886. Formou-se em Engenharia Civil e bacharelou-se em Ciências

Físicas e Matemáticas pela Escola Politécnica da Bahia em 1905 Em 1906, nomeado engenheiro da Comissão Fiscal do Porto da Bahia. Exerceu os cargos eletivos de vereador, deputado federal, senador e governador da Bahia no período de 1947 a 1951. Faleceu no Rio de Janeiro em 1960. (PANTOJA, 2001)

(5) Nasceu em Salvador, Bahia, em 1908. Bacharel em Direito em 1931 pela Faculdade de Direito da Bahia. Em 1951, foi transferido para - Ministério de Educação e Cultura, onde chefiou o gabinete do ministro Simões Filho. Faleceu no Rio de Janeiro em 1978. (GOUVÊA, 2008)

(6) Nasceu em Salvador no dia 6 de novembro de 1874. Em 1894. graduou-se bacharel em ciências jurídicas e sociais na Faculdade de Direito de Pernambuco. Governador da Bahia no período de 1924 a 1928. Faleceu em Salvador no dia 29 de janeiro de 1932. (SAMPAIO, [2001]) em 1951, Secretário Geral da CAPES; 1952, INEP, ${ }^{2}$ 1955- Diretor do CBPE. Permaneceu nestes cargos até o golpe civil-militar de 1964.

\section{Os sete encontros capitais do intelectual Anísio Teixeira}

Os critérios fixados para a definição dos sete encontros capitais de Anísio Teixeira foram os seguintes: indivíduos que acompanharam o educador nas lutas em prol da educação pública e laica; segundo, companheiros que nos momentos difíceis permaneceram fiéis ao projeto que os unia - muitas vezes com discordâncias - e, terceiro, elementos que vindos de áreas distantes das questões educacionais empenharam esforços nesta mesma luta. Por conseguinte, foi no âmbito da criação e do gerenciamento de instituições que se deram os encontros.

\section{Os executivos baianos}

Jayme $A b r e u^{3} e$ Anísio Teixeira estreitaram relação a partir da nomeação de Abreu para um cargo técnico na Secretaria de Educação do Estado da Bahia em 1942, haja vista que cinco anos depois, Otávio Mangabeira, ${ }^{4}$ governador eleito em 1946 convidou Teixeira para Secretário de Educação e Saúde e este de imediato requisitou Jayme Abreu para o seu gabinete no cargo de assessor.

A relação entre os dois foi se adensando e em 1949 nomeou Abreu para a Superintendência do Ensino Médio. A ida de Teixeira para o Distrito Federal afastou por pouco tempo os dois baianos, pois em 1953 - já na direção do INEP - Teixeira convidou Abreu para Diretor Executivo da Campanha de Levantamentos do Ensino Médio e Elementar (CILEME). Ao se edificar o CBPE, foi convidado por Teixeira para ser responsável pela Divisão de Estudos e Pesquisas Educacionais, cargo que exerceu até 1973.

O segundo executivo baiano, Péricles Madureira de Pinho, veio da área jurídica e possuía também conhecimentos da área econômica. Pinho conheceu Teixeira através do seu pai Bernardino Madureira de Pinho - que foi Secretário de Polícia e Segurança Pública de Góis Calmon ${ }^{6}$ ao qual também serviu Teixeira no período de 1924 a 1928. O momento de maior aproximação entre os dois aconteceu, um pouco depois, exatamente no ano de 1929.

Nos anos 1930, Teixeira e Pinho permaneceram distantes haja vista ter o primeiro iniciado os trabalhos à frente do Ministério da Educação, logo sendo convidado para participar do governo Pedro 
Ernesto $^{7}$ e Pinho ter ingressado no alto escalão do Ministério da Fazenda. Porém, em 1951, Pinho foi transferido para o Ministério da Educação e Cultura a fim de chefiar o gabinete do Ministro Ernesto Simões Filho ${ }^{8}$ que também convocou Teixeira. Deste modo, um novo encontro, porém em âmbito ministerial.

Pinho participou ativamente dos momentos anteriores à criação do CBPE e, exerceu o cargo de Ministro da Educação no período de 26 de maio a 24 de junho de 1953. Teve um papel decisivo para a criação do Centro de Documentação Pedagógica (CDP) nesse mesmo ano. Além disto, coube a Pinho a missão de instalar a Casa do Brasil na Cidade Universitária de Paris, um projeto pensado em 1952 com as construções iniciadas em 1956 e, segundo o Boletim Mensal do Centro Brasileiro de Pesquisas Educacionais (BRASIL, 1959, p. 3), somente concluídas em 1959. Do mesmo modo que Jayme Abreu, Pinho teve destacado papel nos embates relativos ao projeto de Lei de Diretrizes e Bases da Educação Nacional que culminou com a aprovação da Lei $n^{\circ} 4.024$ de 1961.

Almir de Castro $^{9}$ - o terceiro executivo baiano - foi designado em 1938 Delegado Federal de Saúde da IV região (que englobava os estados do Rio Grande do Norte, Paraíba, Pernambuco e Alagoas) ficando neste posto até 1940. Nesse ano ingressou como assistente no Serviço de Estudo das grandes Endemias do Instituto Oswaldo Cruz, indo em seguida para os EUA, onde obteve em 1941, o diploma de Master of Public Health, pela Universidade John's Hopkins.

De volta ao Brasil em 1942, foi chefe da seção de Administração da Divisão de Organização Sanitária para, em seguida, ser convidado a dirigir o recém-criado Serviço Nacional de Peste do Ministério da Educação e Saúde. Quando houve o desmembramento do referido Ministério, Castro optou pelo Ministério da Educação e Cultura e em 1954 foi nomeado Diretor-Executivo da CAPES por Anísio Teixeira. (FONSECA, 2000) No início de 1964 assumiu, a convite de Anísio Teixeira, a vice-reitoria da Universidade de Brasília (UnB), que acumulou com as funções na CAPES, sendo exonerado dos dois cargos logo após o golpe civil-militar.
(7) A atuação de Anísio Teixeira na gestão de Pedro Ernesto no Rio de Janeiro (DF), anos 1930, pode ser encontrada em Nunes (2000).

(8) Nasceu em Cachoeira, Bahia, no dia 4 de outubro de 1886. Formou-se na Faculdade Livre de Direito da Bahia em 1907. Fundou em 1912 o jornal A Tarde. Exerceu os cargos eletivos de deputado estadual e deputado federal. Ocupou o cargo de Ministro da Educação no período de 1951 a 1953 no governo Vargas. Faleceu no dia 24 de novembro de 1957 na Bahia. (COUTINHO, 2001)

(9) Nome completo Almir Godofredo de Almeida e Castro. Nasceu em Salvador, Bahia, em 4 de dezembro de 1910. Formado pela Faculdade Nacional de

Medicina em 1931. Faleceu no Rio de Janeiro em data desconhecida. Disponível em:< http://cpdoc.fgv. $\mathrm{br} /$ producao intelectual/arq/1319 Capes04.pdf $>$. 
(10) Nasceu em São Gonçalo de Sapucaí, Minas Gerais, a 2 de abri de 1894. Em 1918 concluiu o curso de ciências jurídicas e sociais na Faculdade de Direito de São Paulo. Jamais advogou. Em 1926, durante a Presidência de Washington

Luís, foi nomeado Diretor-geral de Instrução Pública do Rio de Janeiro ao tempo em que Antônio Prado Júnior (1880-1955) foi prefeito do Distrito Federal. Em 1932, atuou como fundador, professor de sociologia educacional e primeiro diretor do Instituto de Educação de São Paulo, mais tarde incorporado à Universidade de São Paulo. No período de 1955 a 1961, instalou e organizou o Centro Regional de Pesquisas Educacionais em São

Paulo, a convite de Anísio Teixeira, diretor do INEP. Faleceu em 18 de setembro de 1974 em São Paulo. (PENNA, 2010)

\section{A irmandade apolítica}

Fernando de Azevedo ${ }^{10}$ e Teixeira se conheceram em 1929 por intermédio de uma carta de Monteiro Lobato que encontrara Anísio Teixeira na América. Mais que uma carta, a missiva selaria uma amizade entre os dois educadores que permaneceu acesa até o falecimento de Teixeira em 1971. Uma amizade que abriu inúmeras portas e planos para o educador baiano e um lenitivo para as dificuldades que vinha enfrentando Azevedo na implementação da reforma educacional no Distrito Federal. Este aspecto está registrado num dos capítulos do livro Figuras do meu convívio da autoria de Azevedo:

[...] Ele (Anísio) nos conquistou a todos, sem o procurar, pela lucidez e força comunicativa da inteligência, a que dava um encanto particular a simplicidade de maneiras. Confesso haver tido logo o pressentimento de seu destino e do papel que lhe estava reservado na história da educação do país. Quando se levantou, já éramos amigos, como previra e desejara Lobato. [...] O Diretor-Geral da Instrução no Distrito Federal, que o recebia, em plena campanha de uma reforma radical de ensino, reanimou-se, nas suas ásperas lutas, com a volta ao Brasil, do ex-Diretor de Instrução no Estado da Bahia [...]. (AZEVEDO, 1973, p. 127)

De fato, o encontro significou a ampliação da rede de relações de Teixeira com a sua aproximação dos educadores oriundos de São Paulo. Um campo, até então, estranho para Teixeira que mais à frente serviu como a sustentação do educador baiano na sua primeira passagem pelo Distrito Federal (1931 a 1935).

Quanto aos primeiros contatos com educadores no plano federal no período assinalado, impõe-se a necessidade de um olhar acurado para a equipe de auxiliares de Teixeira neste desafio no início dos anos 1930. Depois de 1930, os principais colaboradores de Fernando de Azevedo ainda permaneceram na Diretoria Geral de Instrução Pública sob o comando de Anísio Teixeira.

Anos mais tarde, precisamente em 1955, a irmandade se lança em mais um desafio: A instalação do Centro Regional de Pesquisas Educacionais de São Paulo. É o próprio Azevedo que no livro "História de minha vida" narra o convite e o desafio frente à instalação do Centro - um convite que revela a confiança existente entre os dois intelectuais. 
O encontro dos dois "apolíticos" - Gilberto Freyre ${ }^{11}$ e Anísio Teixeira - ocorreu na condição de assistentes de gabinete de dois políticos: Francisco Góis Calmon e Estácio de Albuquerque Coimbra, respectivamente governadores da Bahia e de Pernambuco no período de 1924 a 1928. É o encontro de dois jovens que, segundo Freyre (1960), os dois governadores desejavam ter como discípulos na arte da política. Este encontro selaria uma amizade que teria como consequências algumas importantes parcerias para o campo das Ciências Sociais. Cabe a referida expressão no lugar de Educação por entender que tais parcerias foram muito amplas, inclusive no processo de criação de instituições de caráter acadêmico como a Escola de Economia e Direito da Universidade do Distrito Federal (UDF) (seção de Ciências Sociais) em 1935, o Instituto Joaquim Nabuco de Pesquisas Sociais, em 1949 e o Centro Regional de Pesquisas Educacionais de Recife, em 1957.

A Gilberto Freyre, foram entregues duas cátedras na UDF: Antropologia e Sociologia Geral. Sobre o convite, Freyre tece o seguinte comentário

[...] Fui dos brasileiros apolíticos procurados por Anísio até nas províncias para colaborarem nesse empreendimento difícil e complexo (a criação da UDF), tão acusado, anos depois, de ter sido puro pretexto a propaganda de caráter sectário ideológico entre a gente môça e desprevenida da capital brasileira [...]. (FREYRE, 1960, p. 121)

Assim, o autodenominado apolítico Gilberto Freyre - 11 anos depois da inauguração da UDF - foi eleito deputado federal por Pernambuco para a Assembleia Constituinte de 1946. Uma das contribuições de Freyre em sua legislatura foi a proposição de criação do Instituto Joaquim Nabuco de Ciências Sociais. Ao menos, um instituto semelhante foi criado um ano após: A Fundação para o desenvolvimento da Ciência na Bahia no governo Otávio Mangabeira, tendo como Secretário de Educação Anísio Teixeira, com os objetivos de coordenar, estimular e assistir a pesquisa e o trabalho científico.
(11) Nasceu em Recife, Pernambucano, em 15 de março de 1900. Em 1918, viajou para os Estados Unidos, onde fez seus estudos universitários: bacharelado em Artes Liberais, com especialização em Ciências Políticas e Sociais, na Universidade de Baylor (EUA) e mestrado e doutorado em Ciências Políticas, Jurídicas e Sociais, na Universidade de Columbia em 1922. Foi eleito deputado federal constituinte, em 1946. Faleceu no Recife em 18 de julho de 1987. (LIMA, 2010) 
(12) Baiano de Livramento do

Brumado. Nasceu em 1902. Bacharel em Direito formado em

1924. Deputado estadual pela

Bahia em 1925. Eleito em 1946

para a Câmara Federal; Chefe do

Gabinete Civil da Presidência da

República em 1961-1962; Ministro

do Trabalho em 1962; Ministro de

Relacões Exteriores no período de

1962-1963, Primeiro Ministro de

1962 a 1963 e, por fim, Ministro do

Supremo Tribunal Federal de 1963

a 1969. Faleceu10 de outubro de

1978, Rio de Janeiro (GOUVÊA,

2008)

\section{O político-partidário}

O próprio Hermes Lima ${ }^{12}$ dá o tom do seu encontro com Anísio Teixeira em 1916:

Nesse ano de 1916, chegara do sertão uma turma de oito ou dez rapazes, alguns deles já com dois ou três anos no colégio São Luís, fundado pelos padres em Caetité, espécie de corte sertaneja, onde a presença da missão protestante desafiava a fé católica. Do grupo, destacavam-se os Teixeiras: Anísio, Jayme e Nelson, todos ótimos estudantes. Mas a auréola de Anísio era já excepcional. (LIMA, 1974, p. 14)

Iniciou-se neste momento uma parceria decisiva para o ingresso de Teixeira no campo educacional o convite feito pelo governador Góis Calmon foi uma indicação feita de Hermes Lima pois "preocupava -o muito o problema da instrução e na procura de alguém para chefiar o respectivo Departamento, lembrei-lhe o nome de Anísio. Ele ouviu, fez perguntas, ponderou e expediu o convite". (LIMA, 1960, p. 132)

Pouco tempo após,

Transferiu-se para o Rio de Janeiro, então Distrito Federal, em 1933, obteve o primeiro lugar em concurso realizado para a cadeira de introdução à ciência do direito da Universidade do Rio de Janeiro. Continuou também a exercer o jornalismo no matutino carioca Diário de Notícias. Em 1935, quando seu conterrâneo Anísio Teixeira ocupava a Secretaria de Educação do interventor Pedro Ernesto Batista, aceitou o convite para dirigir a Faculdade de Direito da Universidade do Distrito Federal. (COUTINHO, 2001, p. 3.150)

Hermes Lima permaneceu na UDF por pouco tempo. A maré repressora de 1935 o encontraria ligado à Aliança Libertadora Nacional - uma frente política que abrigou os intelectuais liberais e socialistas como contraponto ao integralismo - que por sua vez estava imbricada com o Partido Comunista do Brasil (PCB) o que ocasionou a sua a sua demissão da cátedra de Direito e a sua prisão por um ano. Da prisão sairia para novamente tentar o jornalismo, porém o Estado Novo obriga-o ao retorno à Bahia de onde voltaria engajado na chamada Esquerda Democrática, dentro da União Democrática Nacional (UDN), posteriormente ao Partido Socialista Brasileiro (PSB) e, por fim, ao Partido Trabalhista Brasileiro (PTB). 
O jovem combatente

A jovialidade de Darcy Ribeiro ${ }^{13}$ aliada à determinação em fazer triunfar as suas ideias - mesmo que muitas vezes de forma um tanto apressada - fizeram dele um parceiro ideal para Anísio Teixeira. A junção do antropólogo e do educador possibilitou a concretização de inúmeros projetos nos anos 1950 e 1960. Uma parceria que em diferentes instantes conseguiu devolver a Teixeira o ânimo para continuar na batalha e, mais do que isso, abriu janelas para a compreensão mais apurada das possíveis contribuições antropológicas e sociológicas ao campo educacional numa cartografia de pesquisa que assentaria o seu direcionamento para a construção de mapas superpostos que dariam subsídios para o entendimento da escola e o seu entorno, da educação em um determinado contexto histórico, político, econômico e social.

O primeiro contato entre Darcy Ribeiro e Anísio Teixeira, mesmo que superficial, ocorreu pelas mãos de Charles Wagley que estava, à época, 1955, contribuindo com os primeiros planos de pesquisa do CBPE. Vejamos as impressões de Darcy sobre Anísio.

[...] Eu o via como aquele intelectual magrinho, pequenininho, indignadozinho, que falava furioso de educação popular, que defendia a escola pública com um calor que comovia. Mas eu não estava nessa. Gostava era do mato, estava era com meus índios, era com os camponeses, com o povão. Estava era pensando na revolução socialista. Anísio até parecia udenista. Eu o achava muito udenóide por sua amizade com o Mangabeirão [Otávio Mangabeira - governador da Bahia no período de 1947 a 1951], e por suas posições americanistas. Seu jeitão não me agradava, ainda que eu reconhecesse nele, mesmo a distância, uma qualidade de veemência, uma quantidade de paixão, que não encontrava em ninguém mais. (RIBEIRO, 1986, p. 209)

Após o breve encontro, Wagley convenceu Anísio a assistir a uma conferência sobre aspectos culturais da vida indígena proferida por Darcy. Vale acompanhar esta passagem.

[...] O certo é que comecei a conferência e, depois de falar uns dez minutos, vi que o Anísio estava aceso, os olhinhos bem apertados, atento, comendo palavra por palavra do que eu dizia [...]. Em dado momento ele começou a murmurar e eu custei a entender o que ele dizia. Vociferava: São uns gregos!
(11) Nasceu em Montes Claros, Minas Gerais, em 26 de outubro de 1922. Em 1946, formou-se em Antropologia pela Escola Livre de Sociologia e Política de São Paulo. No período de 1947-1956 trabalhou no Serviço de Proteção ao Índio. Em 1957, foi nomeado por Anísio Teixeira diretor da Divisão de Estudos Sociais do Centro Brasileiro de Pesquisas Educacionais. Foi encarregado em 1959, pelo presidente

Juscelino Kubitschek de planejar a Universidade de Brasília. Em 1961, exerceu o cargo de primeiro reitor da Universidade de Brasília. Atuou como ministro da Educação do Gabinete parlamentarista presidido por Hermes Lima (presidente da República: João Goulart). Entre 1963-1964, foi Chefe do Gabinete Civil da Presidência da República, com João Goulart. Em 1964. exilado no Uruguai. Anistiado em 1979, tornou-se professor titular da Universidade Federal do Rio de Janeiro, no Instituto de Filosofia e Ciências Sociais. De 1983 a 1986 foi vice-governador, secretário de Cultura e coordenador do Projeto Especial de Educação do Rio de Janeiro. Foi senador da República de 1991 a 1997. Faleceu em Brasília, no dia 17 de fevereiro de 1997. (GOMES, 2010) 
São uns gregos! [...]. Com essas interjeições ele abriu uma espécie de diálogo louco comigo. [...] Naquele dia começou a amizade de Anísio por mim e, sobretudo, a minha paixão pelo Anísio. (RIBEIRO, 1986, p. 210)

Não tardou o convite para que Darcy dirigisse a Divisão de Estudos e Pesquisas Sociais do CBPE.

[...] Mediante uma recomendação de Charles Wagley, que na época participava na elaboração do plano de pesquisa do CBPE, Darcy Ribeiro foi convidado por Anísio Teixeira para coordenar a Divisão de Estudos e Pesquisas Sociais (DEPS) do CBPE. Apesar de sua experiência profissional passar ao largo da reflexão sobre as questões da educação brasileira, sua história pregressa o colocava em posição favorável para ocupar o cargo com o qual Anísio lhe acenava. Na DEPS, Darcy Ribeiro foi um elemento importante pois estabeleceu pontes entre o centro e a universidade, chamando a participar da experiência os pesquisadores provenientes dos dois principais núcleos de formação de cientistas sociais do país na época, a FFCL da USP e ELSP (XAVIER, 1999, p. 109).

Cabe ressaltar que, além desta, Ribeiro construiu outras pontes que possibilitaram a consecução de diversos projetos do CBPE. Porém, numa perspectiva de mão dupla, foi com a participação ao lado de Teixeira e de sua equipe que Darcy Ribeiro alcançou visibilidade em âmbito nacional como educador.

- Na luta pela criação da Universidade de Brasília, Ribeiro utilizou os contatos políticos e as afinidades regionais para a sustentação de todo o processo de elaboração, construção e funcionamento da referida instituição. Findo o governo Juscelino Kubitschek (31 de janeiro 1956 a 31 de janeiro de 1961) e ainda não consumada a construção da universidade, Ribeiro foi apresentado por Anísio Teixeira ao presidente Jânio Quadros (31 de janeiro a 25 de agosto de 1961) a quem Quadros confiara a elaboração do plano de educação do seu governo. Mais tarde, aproveitou com sucesso o momento da renúncia do presidente para colocar na pauta de votações do Congresso a aprovação do projeto de criação da Universidade de Brasília. No governo João Goulart (8 de setembro de 1961 a $1^{\circ}$ de abril de 1964), Ribeiro foi Ministro da Educação e Chefe da Casa Civil. Como já assinalado, a parceria entre Teixeira e Ribeiro foi uma comunhão de esforços em busca da legitimação de projetos com o lançamento 
de estratégias políticas e de uma dose de afinidades regionais exploradas pelos dois atores. Um encontro capital que teria na capital do Brasil o seu último encontro.

\section{Considerações finais}

Desta forma, o objetivo deste artigo, mesmo na contramão do que o próprio Anísio Teixeira e os seus colaboradores procuraram erigir como uma atuação apolítica ou despolitizada, revelou a utilização de uma estratégia de renúncia ao enfrentamento direto no campo político. Ou seja, a existência de um processo outro de politização que se assentou na tentativa de estabelecer exatamente o mesmo enfrentamento só que de forma indireta.

Os sete encontros capitais do intelectual revelam as redes relacionais estabelecidas, uma tessitura que fortaleceu uma estratégia de permanência no âmbito do Ministério de Educação e Cultura. Redes, que no entendimento de Elias (1994), se ligam em forma de reciprocidade e coesão que se torna tarefa complexa compreender a ação isolada de um intelectual sem operar a leitura da posição do conjunto de atores. Dessa forma, uma atuação organizada e com objetivos a serem executados. Os intelectuais estudados neste artigo projetaram a influência do seu grupo por diversas áreas que não somente a educacional.

Mais do que isto, os setes encontros capitais de Anísio Teixeira permitem pensar as afinidades eletivas e regionais dos intelectuais baianos no âmbito do governo federal no período de 1951 a 1964 . Foram "atores do político", conforme assinala Sirenelli (2013, p. 231), por terem uma intensa participação nos debates sobre as questões educacionais, de forma específica na tramitação da primeira Lei de Diretrizes e Bases da Educação Nacional (n 4.024/61) em relação à destinação das verbas públicas para a educação. Assinaram manifestos em defesa desta mesma escola pública. Criaram revistas e boletins como estratégias de intervenção no fazer pedagógico e na organização da escola pública brasileira.

A própria obra de Anísio Teixeira desautoriza um olhar apolítico para o seu pensamento e suas ações. Livros como A educação e a crise brasileira (1956); Educação não é privilégio (1957) e Educação é um direito (1968), dentre diversos artigos e entrevistas, pelo próprio título, autorizam a leitura crítica e politizada de Teixeira. Mesmo no agudo ano de 1968, um dia após a aplicação do Ato Institucional no 5 que fechou 
o Congresso Nacional, Teixeira publicou no jornal Folha de S.Paulo no dia 14 de julho o artigo "Sombras e Ameaças". Um trecho parece fundamental para a compreensão do debate suscitado por este artigo:

[...] Daí não me surpreender, mas sobremodo me alarmar, a volta ao uso da violência pela autoridade no Brasil. A violência está sempre implícita na ação do governo brasileiro. A liberdade sempre foi uma permissão entre nós, que a cada momento podia ser suspensa. Crise como a que estamos vivendo, hoje, no Brasil, podem ter a vantagem de ajudar-nos a penetrar e perceber a realidade, neste país em que reflexos e sombras são tudo que se pode ver do fundo da caverna em que vivemos, que não é a dos filósofos gregos, mas a dos nossos sertanejos perdidos na extensão continental do país e a da imensidão urbana dos pobres do Brasil, todos na verdade brandos, silenciosos e tão imóveis quanto o velho solo arcaico brasileiro à prova de terremotos. Uma mais aguda consciência de nossa realidade pode fortalecernos, mas não diminui a gravidade das ameaças que pairam no ar. Essas ameaças são as de poder estar-se a ressuscitar e restaurar a real tradição autoritária do país, fazendo-o voltar às suas origens hispânicas e portuguesas. Não esqueçamos que as nações que nos colonizaram têm uma vocação irresistível para os regimes de força e, ainda hoje, vivem sob o jugo de ditadores vitalícios. Dessa vocação não estamos imunes e não posso encarar o que vem ocorrendo no país, sem sentir percorrer-me a espinha o frio desse doloroso pressentimento. Encontro forças apenas na crença, que me vem de Platão, e é a de que o mundo é mais imprevisível do que o possa imaginar a nossa vã capacidade de pressentimento.

Assim, existiu, de fato, a atuação política, a articulação política e a educação como política de um Estado democrático que em nada comprometem ou denigrem a obra de Teixeira. Além do mais, trazer à tona tal processo de politização é uma possível resposta a tantos quantos identificam o projeto anisiano como "neutro" ou "despolitizado". Na contramão da propalada "apoliticidade" em relação às ações e projetos de Teixeira, lê-se em Velho (1997, p. 33-34), a seguinte afirmação: "na medida em que um projeto social represente algum grupo de interesse, terá uma dimensão política, embora não se esgote a esse nível pois a sua viabilidade política propriamente dependerá de sua eficácia em mapear e dar um sentido às emoções e sentimentos individuais." 
Os projetos constituem, portanto, uma dimensão da cultura, na medida em que sempre são expressão simbólica. Sendo conscientes e potencialmente públicos, estão diretamente ligados à organização social e aos processos de mudança social. Assim, implicando relações de poder são sempre políticos.

Portanto, houve uma politização em outros termos: a politização através de uma "estratégia doce" que na batalha utilizou de maneira direta e pública os quadros técnicos do CBPE, do INEP e da CAPES e de forma indireta os quadros políticopartidários acionados em postura de alarido ou de silêncio. Ambos os quadros numa ação articulada buscaram - numa perspectiva alinhavada pelos sete encontros capitais - a legitimação do projeto de Teixeira e dos seus colaboradores no período de 1951 a 1964. Período de 13 anos. Período de 13 ministros no comando da educação pública brasileira no âmbito federal.

\title{
Baianos are likethat: within elective and regional affinities the presence of Anísio Teixeira andother Bahian intellectuals in the Ministry of Education in the 1950s and 1960s
}

\begin{abstract}
The present work seeks to understand the trajectory and permanence of the Bahian intellectuals Anísio Teixeira, Jayme Abreu, Almir de Castro and PériclesMadureira de Pinhoahead of the main pedagogical departments of the Ministry of Education from 1951 to 1964. It is worth mentioning the centrality of Anísio Teixeira in this process, considering that the power spaces occupied by him, as General Secretary of Coordenação de Aperfeiçoamento de Pessoal de Nível Superior (1951), Director of Instituto Nacional de Estudos e Pesquisas Educacionais (1952) and Director of Centro Brasileiro de Pesquisas Educacionais (1955), provided the invitations to the other Bahian intellectuals to serve as executive directors in these institutions. The methodology will be based on the confrontation of memories, interviews, collections, correspondence, institutional reports and pedagogical forms, with the perspective of apprehending the network that gave support to the permanence of these actors within the scope of the state bureaucracy, more specifically, in the cabinet related to education, which witnessed the passage of thirteen titular ministers during the term under review. It is a research that intends to think the construction of a type of politicization of thought and educational action of the actors within a complex network of political-partisan plots in a model of state under national-developmentalist orientation.
\end{abstract}

Keywords: Anísio Teixeira. Trajectory of intellectuals. Bahian intellectuals. Ministry of Education. Brazil, 1950-1960. 


\title{
Son así los bahianos: entre afinidades electivas y regionales la presencia de Anísio Teixeira y de los intelectuales bahianos en el Ministerio de Educación en los años 1950 y 1960
}

\begin{abstract}
Resumen: El presente trabajo busca compreender la trayectoria y la permanencia de los intelectuales bahianos Anísio Teixeira, Jayme Abreu, Almir de Castro y Péricles Madureira de Pinho al frente de los principales sectores pedagógicos del Ministerio de Educación en el período de 1951 a 1964. Cabe ressaltar la centralidad de Anísio (1951), diretor del Instituto Nacional de Estudos e Pesquisas Educacionais (1952) y Director del Centro Brasileiro de Pesquisas Educacionais (1955), propiciaron las invitaciones a los demás intelectual es bahianos a ejercer el papel de diretor es ejecutivos em dichas instituciones. La metodologia tendrá como objetivo laconfrontación entre memorias, entrevistas, acervos, correspondencias, informes institucionales e impresos pedagógicos em la perspectiva de aprehenderlared que dio la sustentación para la permanencia de dichos actores em el ámbito de la burocracia estatal, más especificamente em la carpeta relacionada a la educación que asistió al paso de trece ministros titulares em el período em pantalla. Se trata de una investigación que tiene la intención de pensar la construcción de una forma de politización del pensamiento y acción educativa de actores en el seno de una red de tramas político-partidarias compleja sem un modelo de Estado de orientación nacional-desarrollista.
\end{abstract}

Palabras chave: Anísio Teixeira. Trayectoria de Intelectuales. Intelectualesbahianos. Ministério de Educación. Brasil, 1950-1960.

\section{Referências}

AZEVEDO, Fernando de. Figuras do meu convívio - retratos de família e de mestres e educadores. 2. ed. rev. e ampl. São Paulo: Duas Cidades, 1973.

BRASIL. Ministério da Educação e Cultura. Boletim Mensal do Centro Brasileiro de Pesquisas Educacionais. Rio de Janeiro: CBPE/INEP/MEC, 20, 3, 1959.

BRITTO, Jaider Medeiros de. Verbete sobre Jayme Abreu. In: Fávero, Maria de Lourdes de Albuquerque Fávero; Britto, Jaider Medeiros de. (Org.). Dicionário de Educadores no Brasil: da Colônia aos dias atuais. Rio de Janeiro: Editora UFRJ/MEC-INEP, p. 264-269, 1999.

COUTINHO, Amélia. Verbete: Hermes Lima. In: ABREU, Alzira Alves de et al. (Coord.). Dicionário histórico-biográfico brasileiro pós-1930. 2. ed. rev. e atualizada. Rio de Janeiro: Editora FGV/CPDOC, 2001, p. 3.150-3.154.

ELIAS, Norbert. A sociedade dos indivíduos. Rio de Janeiro: Jorge Zahar Ed, 1994.

FONSECA, Cristina M. Oliveira.Trabalhando em saúde pública pelo interior do Brasil: lembranças de uma geração de sanitaristas (19301970). Ciência e Saúde Coletiva, Salvador, v. 5, n. 2, p. 393-411, 2000. 
FREYRE, Gilberto. Anísio Teixeira: um depoimento. In: Lima, Hermes. Anísio Teixeira: pensamento e ação. Rio de Janeiro: Ed. Civilização Brasileira, 1960, p. 118-125.

GOMES, Candido Alberto. Darcy Ribeiro. Brasília, DF: MEC, 2010. (Coleção Educadores).

KOSELLECK, Reinhart. Futuro passado: contribuição à semântica dos tempos históricos. Rio de Janeiro: Contraponto: Ed. PUC-Rio, 2006.

LEVILLAIN, Philippe. Os protagonistas: da biografia. In: Rémond, Réne (Org.). Por uma história política. 2. ed. Rio de Janeiro: Editora FGV, 2003, p. 141-184.

LIMA, Hermes. Travessia: memórias. Rio de Janeiro: José Olympio, 1974.

LIMA, Hermes. Anísio Teixeira: pensamento e ação. Rio de Janeiro: Ed. Civilização Brasileira, 1960.

LIMA, Mário Hélio Gomes de. Gilberto Freyre. Brasília: MEC, 2010. (Coleção Educadores).

NUNES, Clarice. Anísio Teixeira: a poesia da ação. São Paulo: EDUSF, 2000 .

PANTOJA, Sílvia. Verbete: Otávio Mangabeira In: ABREU, Alzira Alves de et al. (Coord.). Dicionário histórico-biográfico brasileiro pós-1930. 2.ed. rev. e atualizada. Rio de Janeiro: Editora FGV/CPDOC, 2001. p. 3.529-3.533.

PENNA, Maria Luiza. Fernando de Azevedo. Coleção Educadores. Brasília: MEC, 2010.

PINHO, Péricles Madureira de. São assim os baianos. Rio de Janeiro: Editora Fundo de Cultura, 1960b.

RIBEIRO, Darcy. Sobre o óbvio. Rio de Janeiro: Guanabara, 1986.

SIRINELLI, Jean-François. Os intelectuais. In: RÉMOND, Réne (Org.). Por uma história política. 2. ed. Rio de Janeiro: Editora FGV, 2003, p. 231270.

TEIXEIRA, Anísio. Sombras e ameaças. Folha de S. Paulo, 14 de dezembro,1968.

VELHO, Gilberto. Individualismo e cultura: notas para uma antropologia da sociedade contemporânea. 4. ed. Rio de Janeiro: Jorge Zahar, 1997.

XAVIER, Libânia Nacif. O Brasil como laboratório: educação e ciências sociais no projeto do Centro Brasileiro de Pesquisas Educacionais CBPE/INEP/MEC (1950-1960). 1999. 290 f. Tese (Doutorado em Educação) - Departamento de Educação, Pontifícia Universidade Católica do Rio de Janeiro, Rio de Janeiro, 1999.

Submetido em 09/08/2017.

Aceito em 09/12/2017. 